OPEN ACCESS

Edited by:

Alberto Farolfi,

Romagnolo Scientific Institute for the

Study and Treatment of Tumors

(IRCCS), Italy

Reviewed by:

Valerio Gallotta,

Catholic University of the Sacred

Heart, Italy

Barbara Costantini,

Catholic University of the Sacred

Heart, Italy

*Correspondence:

Zhong-qiu Lin

zhongqiu_lin@163.com

Jing $\mathrm{Li}$

lijing228@mail.sysu.edu.cn

†These authors have contributed equally to this work

Specialty section:

This article was submitted to

Women's Cancer,

a section of the journal

Frontiers in Oncology

Received: 11 October 2020 Accepted: 18 February 2021

Published: 11 March 2021

Citation:

Chan C-y, Li H, Wu M-f, Liu C-h, Lu H-w, Lin Z-q and Li J (2021) A Dose-Finding Trial for Hyperthermic

Intraperitoneal Cisplatin in

Gynecological Cancer Patients

Receiving Hyperthermic

Intraperitoneal Chemotherapy.

Front. Oncol. 11:616264.

doi: 10.3389/fonc.2021.616264

\section{A Dose-Finding Trial for Hyperthermic Intraperitoneal Cisplatin in Gynecological Cancer Patients Receiving Hyperthermic Intraperitoneal Chemotherapy}

\author{
Chui-ying Chan ${ }^{\dagger}$, Hui Li ${ }^{\dagger}$, Miao-fang Wu, Chang-hao Liu, Huai-wu Lu, Zhong-qiu Lin* and \\ Jing $L i^{*}$
}

Department of Gynecologic Oncology, Sun Yat-sen Memorial Hospital, Sun Yat-sen University, Guangzhou, China

Background: To identify the maximum tolerated dose (MTD) of hyperthermic intraperitoneal cisplatin at $43^{\circ} \mathrm{C}$ among gynecological cancer patients.

Methods: In this Phase I dose-finding trial, Bayesian optimal interval (BOIN) design was used. We sought to explore the MTD with a target dose-limiting toxicity (DLT) rate of 20\%, 4 prespecified doses $\left(70 \mathrm{mg} / \mathrm{m}^{2}, 75 \mathrm{mg} / \mathrm{m}^{2}, 80 \mathrm{mg} / \mathrm{m}^{2}\right.$ and $\left.85 \mathrm{mg} / \mathrm{m}^{2}\right)$, and 30 patients.

Results: Between 2019 and 2020, 30 gynecologic cancer patients were enrolled. No patients received bevacizumab in subsequent treatment. The most common adverse events related to cisplatin were nausea and vomiting (100\%), followed by tinnitus (26.7\%) and kidney injury (23.3\%). Of the seven patients with kidney injury, four had persistent renal impairment, and finally progressed into chronic kidney injury. DLTs were noted only in the dose level 4 group $\left(85 \mathrm{mg} / \mathrm{m}^{2}\right)$ and included acute kidney injury, pulmonary embolism, anemia, and neutropenia. When cisplatin was given at dose level four $\left(85 \mathrm{mg} / \mathrm{m}^{2}\right)$, the isotonic estimate of the DLT rate (22\%) was closest to the target DLT rate of $20 \%$. Therefore, $85 \mathrm{mg} / \mathrm{m}^{2}$ was selected as the MTD, with a $51 \%$ probability that the toxicity probability was greater than the target DLT rate.

Conclusions: For gynecological cancer patients who received HIPEC for peritoneal metastases, the MTD of cisplatin in HIPEC at $43^{\circ} \mathrm{C}$ was $85 \mathrm{mg} / \mathrm{m}^{2}$. Our findings apply to patients who do not receive bevacizumab (ChiCTR1900021555).

Keywords: Bayesian optimal interval design, dose-finding trial, cisplatin, gynecological cancer, hyperthermic intraperitoneal chemotherapy, kidney injury, maximum tolerated dose

\section{INTRODUCTION}

Peritoneal metastasis (PM) is a common manifestation of gynecological carcinomas and has significantly negative influence on patient prognosis (1). For PM patients, a combination of cytoreduction and hyperthermic intraperitoneal chemotherapy (HIPEC) is an important treatment option. Malignant cells can be killed by hyperthermia in the range of $41-43^{\circ} \mathrm{C}$ (2). Heat can also change drug pharmacokinetics and increase the cytotoxicity of certain cytotoxic drugs (1). In addition, previous clinical studies have noted improved survival outcomes among PM patients 
treated with HIPEC (3-5). On the basis of this evidence, many guidelines recommend HIPEC for gynecological cancer patients with PM (6-8).

Cisplatin is one of the first-line drugs used in HIPEC (6, 7). However, the optimal cisplatin dose regimen for HIPEC is still uncertain. The reported doses of cisplatin in the literature vary significantly, ranging from 15 to $150 \mathrm{mg} / \mathrm{m}^{2}(1,9)$. The recommend dose in the National Comprehensive Cancer Network (NCCN) guidelines is $100 \mathrm{mg} / \mathrm{m}^{2}$ (6), which is based on a randomized controlled trial (RCT) in which 245 ovarian cancer patients were randomized to receive interval debulking surgery (IDS) either with or without HIPEC (4). Although the authors reported that the addition of HIPEC did not result in an increased rates of side effects, several aspects of this trial deserve attention. First, the authors did not detail cisplatin-related adverse events (AEs) completely. Second, all patients received sodium thiosulphate during the procedure of HIPEC to alleviate cisplatin-related nephrotoxicity, so the real nephrotoxicity induced by hyperthermic cisplatin remains unclear. Finally, the administration of cisplatin in the trial was according to the following schedule: $50 \%$ of the dose at start, $25 \%$ at $30 \mathrm{~min}$ and $25 \%$ at $60 \mathrm{~min}$. In this way, the maximum dose in the abdomen was lower than $100 \mathrm{mg} / \mathrm{m}^{2}$. Collectively, it is hard to reach a definite conclusion that a dose of $100 \mathrm{mg} / \mathrm{m}^{2}$ of cisplatin is safe for HIPEC. Since most cisplatin-related AEs are dose dependent (10), the lack of a standard dose has a major impact on the safe application of HIPEC. Two dose-finding trials for cisplatin in HIPEC have been published $(11,12)$. However, the designs of these trials are methodologically arguable. The two trials enrolled only European patients, and many patients received bevacizumab following HIPEC. Given the influence of race differences and the nephrotoxicity of bevacizumab (13-15), the conclusions of those studies may not be generalizable to other patient groups. Additionally, the treatment temperatures of HIPEC in the published literature are different from the recommended temperature in the Chinese Anti-cancer Association (CACA) guidelines (7). Since the toxicity of some chemotherapeutic drugs is temperature dependent (16), it is necessary and important to explore the dosing regimen at a given temperature. Herein, utilizing Bayesian optimal interval (BOIN) design, we initiated a Phase I dose-finding trial to explore the maximum tolerated dose (MTD) of hyperthermic intraperitoneal cisplatin at $43^{\circ} \mathrm{C}$ in gynecological cancer patients.

\section{MATERIALS AND METHODS}

\section{Study Design and Patient Eligibility}

The present study is an open-label Phase I dose-finding trial which was carried out at Sun Yat-sen Memorial Hospital. The study was conducted according to the Declaration of Helsinki. The study protocol was approved by the Institutional Review Board of Sun Yat-sen Memorial Hospital and registered at Chinese Clinical Trial Registry (ChiCTR, http://www.chictr.org. cn/abouten.aspx, ChiCTR1900021555). Registration occurred before the start of the trial and before any patients were enrolled. This article adheres to the CONSORT (Consolidated Standards of
Reporting Trials) guidelines. All patients provided signed written informed consent obtained before enrollment. Patients were recruited at the Department of Gynecologic Oncology of Sun Yat-sen Memorial Hospital from January 2019 and January 2020.

The primary objective of the present study was to identify the MTD for hyperthermic intraperitoneal cisplatin at $43^{\circ} \mathrm{C}$. Secondary outcomes were hyperthermic cisplatin induced serious AEs that mainly include major kidney dysfunction that required emergent dialysis and visceral perforation $(11,13,17)$ and short-term survival outcomes.

Gynecological cancer patients who fulfilled the indication of HIPEC according to CACA guidelines were eligible if they met all the following criteria (7): age between 18 and 65 years; adequate renal function (blood creatinine: 58-96 $\mu \mathrm{mol} / \mathrm{L}$ ), bone marrow function (hemoglobin $\geq 110 \mathrm{~g} / \mathrm{L}$, white cell count $\geq 4.0 \times$ $10^{9} / \mathrm{L}$, neutrophil count $\geq 2.0 \times 10^{9} / \mathrm{L}$, platelet count $\geq 100 \times$ $10^{9} / \mathrm{L}$ ) and hepatic function [bilirubin 3.4-22.2 $\mu \mathrm{mol} / \mathrm{L}$, alanine aminotransferase (ALT) 7-40 U/L, aspartate aminotransferase (AST) 13-35 U/L, AST/ALT $\leq 1.5]$. Patients were excluded if they had been treated with cisplatin for any reason within 3 weeks prior to HIPEC.

\section{Treatment Plan}

Following cytoreduction or biopsy, four tubes were placed (two in the bilateral subdiaphragmatic space for use as inlet tubes and two in the pelvic cavity for use as an outlet tubes) which were used to administrate HIPEC (18). Due to limited HIPEC equipment, we initially had planned to administer HIPEC within $48 \mathrm{~h}$ of surgery, but all patients received HIPEC immediately after surgery while the trial was actually being carried out. Cardiac, renal, hepatic, and bone marrow function were re-evaluated prior to the initiation of HIPEC. A high precision hyperthermic intraperitoneal perfusion treatment system (approved by the State Food Drug Administration of China, approval No. 20093260924) was used. The system has a precision of $\pm 0.10^{\circ} \mathrm{C}$ for temperature control and $\pm 5 \%$ for flow control. Cisplatin was added to $3,000-5,000 \mathrm{~mL}$ of saline solution and administered at $43 \pm 0.10^{\circ} \mathrm{C}$. The HIPEC procedure consisted of a $30 \mathrm{~min}$ preheating period and a $60 \mathrm{~min}$ perfusion period. During the treatment, vital signs and urine output were monitored continually. Intravenous hydration was required for all patients. It was started $1 \mathrm{~h}$ before the initiation of HIPEC and maintained until $24 \mathrm{~h}$ after the completion of treatment. After HIPEC, followup visits were scheduled weekly for the first 3 weeks, then every 3 weeks for 3 months and every 3-6 months thereafter.

\section{Statistical Analysis}

The MTD was explored with a target DLT rate of $20 \%, 4$ prespecified doses $\left(70,75,80\right.$, and $\left.85 \mathrm{mg} / \mathrm{m}^{2}\right)$ and 30 patients. Patients were treated in cohorts of three. A BOIN design was used to identify the MTD of escalating doses of cisplatin (19). Figure 1 shows the BOIN design and summarizes the trial protocol. The Data and Safety Monitoring Board (DSMB) reviewed all toxic effects and made decisions on dose escalation. Cisplatin-related serious AEs during HIPEC have been reported in many studies, including major kidney dysfunction that required emergent dialysis and visceral perforation $(11,13,17)$. Considering these 


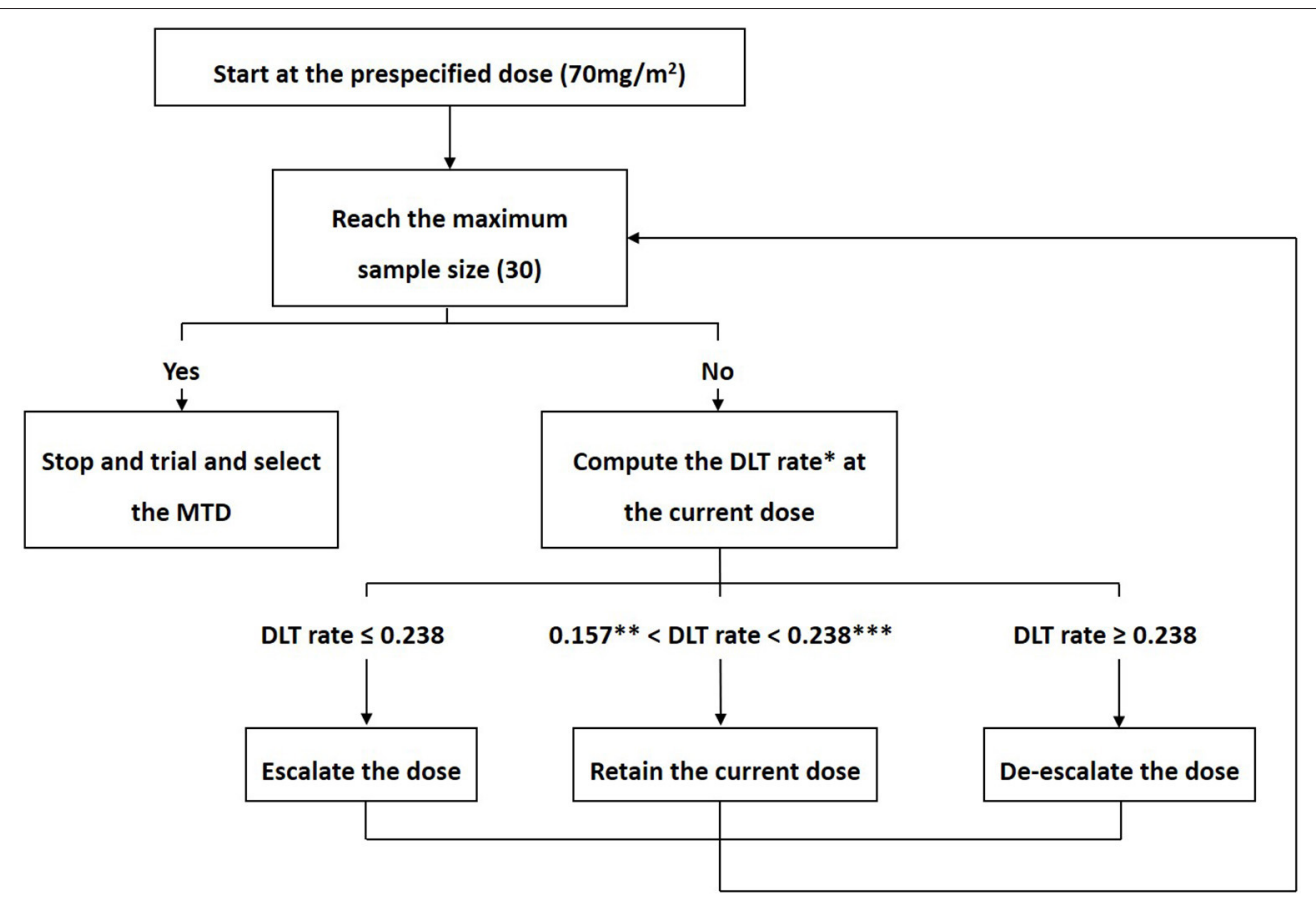

FIGURE 1 | Bayesian optimal interval design. According to the Bayesian optimal interval (BOIN) design, the decision to escalate or de-escalate the dose was made by a comparison of the observed dose-limiting toxicity (DLT) rate $(\hat{p})$ at the current dose with fixed prespecified dose escalation $\left(\lambda_{e}\right)$ and de-escalation $\left(\lambda_{d}\right)$ boundaries. We sought to explore the maximum tolerated dose (MTD) with a target DLT rate of $20 \%, 4$ prespecified doses $(70,75,80$, and 85 mg/m²) and 30 patients. The corresponding dose escalation and de-escalation boundaries were $\lambda_{e}=0.157$ and $\lambda_{d}=0.238$, respectively. The trial protocol was generally described as follows. (1) The first cohort of three patients received cisplatin at a dose of $70 \mathrm{mg} / \mathrm{m}^{2}$. (2) If $\hat{p} \leq \lambda_{e}$, the dose was escalated; If $\hat{p} \geq \lambda_{d}$, the dose was de-escalated; If $\lambda_{e}<\hat{p}<\lambda_{d}$, the current dose was retained. (3) Step 2 was repeated until the maximum sample size was reached.

${ }^{*} \mathrm{DLT}$ rate $=\frac{\text { Total number of patients who experienced } D L T \text { at the current dose }}{\text { Total number of patients taking the current dose }}$

${ }^{\star *} 0.157, \lambda$ c, which represents the dose escalation boundary.

${ }^{\star \star \star} 0.238, \lambda d$, which represents the dose de-escalation boundary.

MTD, maximum tolerated dose; DLT, dose-limiting toxicity.

reports and patient safety, DSMB recommended the use of grade 3 AEs, rather than grade 4 AEs, to define DLT. When the trial was completed isotonic regression was performed which pooled information across doses and obtained an estimate of the MTD. DLT was defined as toxic effects that were associated with cisplatin within 3 weeks following HIPEC, which included (1) death; (2) digestive, hepatobiliary or pancreatic perforation or fissure requiring surgery; (3) hemorrhage requiring transfusion or surgery; (4) life-threatening or irreversible disability; and (5) grade $\geq 3$ adverse events according to the National Cancer Institute Common Terminology Criteria for Adverse Event (CTC-AE) Version 4.0 classification. Kidney injury was divided into acute kidney injury (AKI), which was observed within 3 days of HIPEC, and late-onset kidney injury (LKI), which was observed within 3-21 days after HIPEC. If kidney injury lasted more than 3 weeks, it was considered chronic kidney injury (CKI). Post-HIPEC complications that were attributable to surgery were not considered DLTs.

The calculation of dose elimination boundaries, the estimation of the $95 \%$ exact confidence interval (CI) for the toxicity rate and the selection of the MTD were completed using the BOIN Design Desktop Program, which was downloaded from the MD Anderson Software Download website (https://biostatistics.
mdanderson.org/SoftwareDownload), as well as an online BOIN design tool (https://ibl.mdanderson.org/BOIN/). Baseline patient characteristics were described with descriptive statistics and analyzed using Stata statistical software (version 15.0, Stata Corp LP, College Station, TX). All statistical tests were towsided, and differences were considered statistically significant at $P<0.05$.

\section{RESULTS}

Between January 2019 and January 2020, 30 gynecological cancer patients were enrolled, and received HIPEC right after surgery. Figure 2 shows the enrolling procedure. The clinicopathologic and treatment characteristics of the patients are listed in Table $\mathbf{1 .}$ Twenty-seven (90\%) patients had a pathological diagnosis of primary ovarian cancer, while $3(10 \%)$ patients had PM from other sites. Before HIPEC, 9 (30\%) patients received only biopsy because of unresectable disease, and they underwent two cycles of intravenous neoadjuvant chemotherapy followed by interval debulking surgery. All 30 patients received subsequent cycles of planned chemotherapy within 3-4 weeks of HIPEC without dose delay or dose reduction, and no patient received bevacizumab. 


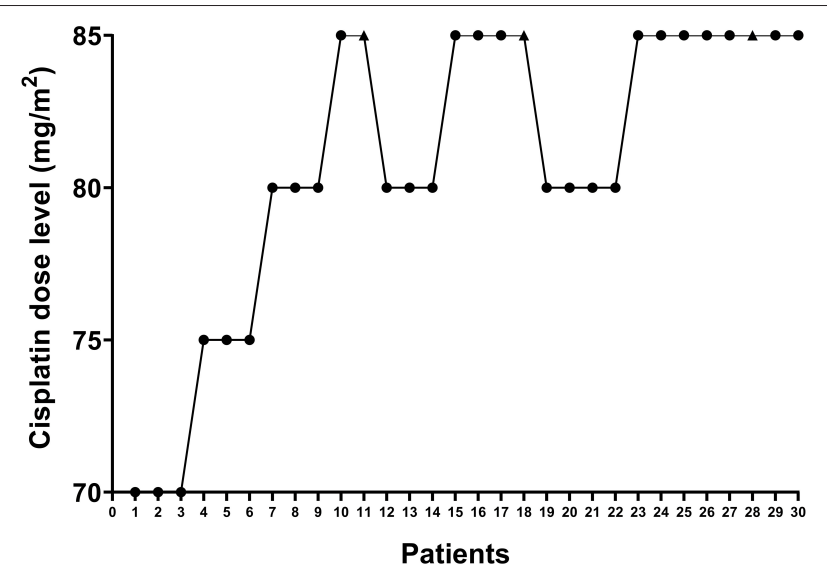

FIGURE 2 | Enrollment of study patients. The $X$-axis shows individual patients who were enrolled sequentially. The $Y$-axis represents the four dose levels (70, 75,80 , and $85 \mathrm{mg} / \mathrm{m}^{2}$ ). The black dots indicate patients who did not develop dose-limiting toxicity, while the black triangles indicate patients who developed dose-limiting toxicity.

Table 2 details AEs that were noted within 3 weeks of HIPEC. The most common AEs were nausea and vomiting (100\%), followed by tinnitus (26.7\%) and kidney injury (23.3\%). No anastomotic leakage or neutropenic fever was observed. The symptoms in patients with nausea and vomiting were relieved within $6-12 \mathrm{~h}$ of symptomatic treatment. Of the seven patients with kidney injury, three $(42.8 \%)$ patients had AKI, and four (57.1\%) had LKI; however, none of them required dialysis. For the four cases of LKI, the diagnosis was made on day $6,20,22$, and 24 after HIPEC. Two of the three AKI patients and two of the four LKI patients had persistent kidney dysfunction and eventually progressed into CKI. All 30 patients received subsequent cycles of chemotherapy within 3-4 weeks of HIPEC.

Among patients who received a cisplatin dose level $\leq 80$ $\mathrm{mg} / \mathrm{m}^{2}$, no grade 3 or higher AEs were observed. Three patients developed DLTs that included AKI (grade 3), pulmonary embolism (grade 3), anemia (grade 3 ) and neutropenia (grade 3 ). All three patients were in the $85 \mathrm{mg} / \mathrm{m}^{2}$ dose group. Based on the observed data, the isotonic estimates of toxicity probabilities of the four doses were 0.01 (exact 95\% CI: 0.00-0.20), 0.01 (exact 95\% CI: 0.00-0.20), 0.01 (exact 95\% CI: 0.00-0.06), and 0.22 (exact 95\% CI: 0.00-0.46). When cisplatin was given at dose level four $\left(85 \mathrm{mg} / \mathrm{m}^{2}\right)$, the isotonic estimate of the DLT rate $(22 \%)$ was closest to the target DLT rate of $20 \%$. Therefore, $85 \mathrm{mg} / \mathrm{m}^{2}$ was selected as the MTD with a $51 \%$ probability that the toxicity probability was greater than the target DLT rate.

The median follow-up time was 8.6 months (range: 3.0-14.6 months). One patient in the $70 \mathrm{mg} / \mathrm{m}^{2}$ dose group developed recurrence 10 months following HIPEC. Two patients died of disease. One patient received cisplatin at a dose of $80 \mathrm{mg} / \mathrm{m}^{2}$ and died of the disease 12 months following HIPEC. The other patient was treated with cisplatin at a dose of $85 \mathrm{mg} / \mathrm{m}^{2}$ and succumbed to her disease 6 months after HIPEC.
TABLE 1 | Descriptive features of patients, tumors and surgical outcomes.

\begin{tabular}{|c|c|}
\hline Variable & \\
\hline Age (years), median (range) & $51(32-65)$ \\
\hline $\begin{array}{l}\text { Body surface area }\left(\mathrm{m}^{2}\right) \text {, median } \\
\text { (range) }\end{array}$ & $1.55(1.28-1.78)$ \\
\hline BMI (kg/m²), median (range) & $22.6(16.4-28.4)$ \\
\hline \multicolumn{2}{|l|}{ Histopathology, $n$ (\%) } \\
\hline Ovarian cancer & $27(90.0)$ \\
\hline Mucinous adenocarcinoma & $3(11.1)$ \\
\hline Serous adenocarcinoma & $19(70.4)$ \\
\hline Endometrioid adenocarcinoma & $1(3.7)$ \\
\hline Clear cell adenocarcinoma & $2(7.4)$ \\
\hline Granulosa cell tumor & $1(3.7)$ \\
\hline Malignant germ cell tumors & $1(3.7)$ \\
\hline Endometrial cancer & $1(3.3)$ \\
\hline Cervical adenocarcinoma & $1(3.3)$ \\
\hline Peritoneal mesothelioma & $1(3.3)$ \\
\hline \multicolumn{2}{|l|}{ Tumor histologic grade, $n(\%)$} \\
\hline Grade 1-2 & $21(70.0)$ \\
\hline Grade 3 & $9(30.0)$ \\
\hline $\begin{array}{l}\text { pre-HIPEC serum creatinine (umol/l), } \\
\text { median (range) }\end{array}$ & $64.5(43-93)$ \\
\hline $\begin{array}{l}\text { pre-HIPEC serum albumin (g/l), } \\
\text { median (range) }\end{array}$ & $33.5(22.2-48.6)$ \\
\hline $\begin{array}{l}\text { Peritoneal cancer index, median } \\
\text { (range) }\end{array}$ & $6(1-30)$ \\
\hline \multicolumn{2}{|l|}{ Surgical procedures, $\boldsymbol{n}(\%)$} \\
\hline Hysterectomy & $13(43.3)$ \\
\hline Salpingo-oophorectomy & $17(56.7)$ \\
\hline Lymphadenectomy ${ }^{*}$ & $8(26.7)$ \\
\hline Small bowel resection & $1(3.3)$ \\
\hline Hepatectomy & $2(6.7)$ \\
\hline Omentectomy & $17(56.7)$ \\
\hline Appendectomy & $12(40.0)$ \\
\hline Diaphragmatic peritonectomy & $3(10.0)$ \\
\hline $\begin{array}{l}\text { Operation time (minutes), median } \\
\text { (range) }\end{array}$ & $172(25-360)$ \\
\hline $\begin{array}{l}\text { Estimated blood loss (ml), median } \\
\text { (range) }\end{array}$ & $50(1-700)$ \\
\hline \multicolumn{2}{|c|}{ Blood transfusion during surgery, $n(\%)$} \\
\hline Yes & $4(13.3)$ \\
\hline No & $26(86.7)$ \\
\hline \multicolumn{2}{|c|}{ Completeness of cytoreduction ${ }^{\star \star}, n(\%)$} \\
\hline $\mathrm{CC}-0$ & $18(85.7)$ \\
\hline $\mathrm{CC}-1+$ & $3(14.3)$ \\
\hline \multicolumn{2}{|l|}{ ICU stay, $n(\%)$} \\
\hline Yes & $1(3.3)$ \\
\hline No & $29(96.7)$ \\
\hline
\end{tabular}

BMI, body mass index; HIPEC, Hyperthermic intraperitoneal chemotherapy; ICU, intensive care unit.

"including pelvic and para-aortic lymphadenectomy.

"21 patients received debulking surgery.

\section{DISCUSSION}

Cisplatin is the preferred agent for HIPEC because of its excellent peritoneal plasma gradient and its synergistic relationship with 
TABLE 2 | Adverse events according to dose level.

\begin{tabular}{|c|c|c|c|c|}
\hline \multirow[t]{2}{*}{ Adverse event, $n$} & \multicolumn{4}{|c|}{ NCI-CTCAE 4.0} \\
\hline & Grade 1 & Grade 2 & Grade 3 & Grade 4 \\
\hline \multicolumn{5}{|l|}{$70 \mathrm{mg} / \mathrm{m}^{2}(n=3)$} \\
\hline hromboembolic events ${ }^{\mathbb{I I}}$ & - & 1 & - & - \\
\hline Bloating & - & 1 & - & - \\
\hline Nausea and vomiting & 3 & - & - & - \\
\hline \multicolumn{5}{|l|}{$75 \mathrm{mg} / \mathrm{m}^{2}(n=3)$} \\
\hline Late-onset kidney injury & - & $1^{*}$ & - & - \\
\hline Intestinal obstruction & - & 1 & - & - \\
\hline Tinnitus & 2 & - & - & - \\
\hline Nausea and vomiting & 3 & - & - & - \\
\hline \multicolumn{5}{|l|}{$80 \mathrm{mg} / \mathrm{m}^{2}(n=10)$} \\
\hline Acute Kidney Injury & 1 & - & - & - \\
\hline Late-onset kidney injury & $2^{\star \star}$ & - & - & - \\
\hline Neutropenia & - & 1 & - & - \\
\hline Intestinal obstruction & 1 & - & - & - \\
\hline Tinnitus & 2 & - & - & - \\
\hline Nausea and vomiting & 10 & - & - & - \\
\hline \multicolumn{5}{|l|}{$85 \mathrm{mg} / \mathrm{m}^{2}(n=14)$} \\
\hline Neutropenia & - & - & 1 & - \\
\hline Anemia & - & - & 1 & - \\
\hline Acute Kidney Injury & - & $1^{*}$ & $1^{\star}$ & - \\
\hline Late-onset kidney injury & - & 1 & - & - \\
\hline Thromboembolic events ${ }^{I I}$ & - & 2 & 1 & - \\
\hline Dizziness & 1 & - & - & - \\
\hline Hypokalemia & - & 2 & - & - \\
\hline Hypocalcemia & - & 2 & - & - \\
\hline Hepatic function impairment & - & 4 & - & - \\
\hline Tinnitus & 4 & - & - & - \\
\hline Nausea and vomiting & 14 & - & - & - \\
\hline
\end{tabular}

NCI-CTCAE, National Cancer Institute Common Terminology Criteria for Adverse Events. IThromboembolic events included venous thrombosis and pulmonary thrombosis. ${ }^{*}$ The patient progressed into chronic kidney injury.

**One patient progressed into chronic kidney injury.

heat $(2,20)$. Two dose-finding studies have been published so far that identified the MTD for cisplatin among patients who received HIPEC $(11,12)$. In Zivanovic's study (12), three dose levels $\left(60,80\right.$, and $\left.100 \mathrm{mg} / \mathrm{m}^{2}\right)$ at $41-43^{\circ} \mathrm{C}$ were investigated, but no definitive MTD was identified. Favorable pharmacokinetic and pharmacodynamic properties of hyperthermic cisplatin were confirmed at all dose levels, especially at $100 \mathrm{mg} / \mathrm{m}^{2}$. Since DLT was observed only in the third dose level $\left(100 \mathrm{mg} / \mathrm{m}^{2}\right)$, the authors concluded that hyperthermic intraperitoneal cisplatin at a dose of $100 \mathrm{mg} / \mathrm{m}^{2}$ has an acceptable safety profile and can be considered the recommended Phase II dose. The other trial by Gouy et al. (11) reached a different conclusion. The authors assessed four dose levels $\left(50,60,70\right.$, and $\left.80 \mathrm{mg} / \mathrm{m}^{2}\right)$ at $42 \pm 1^{\circ} \mathrm{C}$. They selected $80 \mathrm{mg} / \mathrm{m}^{2}$ as the MTD, as all DLTs were noted at this dose level. However, based on the observed DLTs and prolonged impairment of renal function, Gouy et al. (11) recommended a cisplatin dose of $70 \mathrm{mg} / \mathrm{m}^{2}$ for HIPEC. Overall, previous studies have yielded no consistent results or conclusions. Variations in ethnical restrictions, patient selection criteria, HIPEC regimens, treatment temperatures and study designs may contribute to the inconsistency.

In the present study, we assessed four cisplatin dose levels at $43^{\circ} \mathrm{C}$, and identified $85 \mathrm{mg} / \mathrm{m}^{2}$ as the MTD. In general, all patients tolerated HIPEC well. No patient developed serious AEs that were reported in previous studies $(11,13)$. Of note, because of unresectable disease, $9(30 \%)$ patients in the present trial received biopsy rather than debulking surgery prior to HIPEC. For them, HIPEC could be considered as part of neoadjuvant treatment. The safety and feasibility of HIPEC in the neoadjuvant setting for gynecologic cancer patients has been reported in our previous study (18). The most notable difference between the current trial and previous studies is the study design. The current trial was based on the BOIN design. Compared with the classical $3+3$ design, which was utilized in Zivanovic's study (12), the BOIN design has superior flexibility (21). The latter design can target any prespecified DLT rate and make decisions regarding dose escalation and de-escalation at any time as long as the DLT rate at the current dose can be calculated. In addition, the BOIN design is more likely to correctly select the MTD and allocate more patients to the MTD group when compared with the $3+3$ design (21). Yuan's numerical study also showed that the BOIN design generally outperforms the $3+3$ design (21). With regard to the continual reassessment method (CRM), which was utilized in Gouy's trial, it has a comparable performance with the BOIN design (19). However, the CRM is statistically and computationally complex and lacks transparency hindering its use in practice $(19,21)$.

Cisplatin-induced kidney injury in HIPEC has been a focus of research. Major kidney injury is noted in $1.3-5.9 \%$ of patients and is characterized by notable ethnical differences (22-24). Sin et al. (13) conducted a retrospective study in Chinese patients who received cisplatin for HIPEC. For patients who developed grade 3 or higher kidney injury, they developed raised creatinine within 2 days of HIPEC, and the maximum creatinine elevation could be observed within 6-19 days of HIPEC. Similar findings were reported in Kusamura' paper (23). Based on the evidence, we classified kidney injury following HIPEC according to the timing of its occurrence. The incidence of kidney injury in the current study was $23.3 \%$, which is consistent with previous reports $(11,13,25)$. However, none of the cases of kidney injury needed to receive dialysis, which is different from the results of other studies $(11,13)$. All of our patients received continuous intravenous hydration which may help ameliorate the severity of renal damage $(26,27)$. On the other hand, of the seven cases of kidney injury, four had persistent renal impairment and finally progressed into CKI. This result and similar findings from other studies imply that HIPEC recipients who develop cisplatininduced renal impairment may be at high risk for CKI $(11,13)$. Although CKI has a significant negative impact on patient quality of life and limits treatment options for cancer patients $(28,29)$, no effective preventive measure is available, which presents a considerable challenge in clinical practice.

The feasibility of combination of HIPEC and bevacizumab has been validated in ovarian cancer patients (30). However, it should be noted that no patient in our cohort received bevacizumab 
following HIPEC. Bevacizumab is also nephrotoxic (29). In a previous study, increases in serum creatinine levels, which are the most common consequence of cisplatin-induced renal injury, were observed among patients who received bevacizumab $(31,32)$. Given that heat can enhance the nephrotoxicity of cisplatin $(2,33)$, we believe cisplatin should be given with greater caution in HIPEC if subsequent bevacizumab is planned, and it may be appropriate to decrease the dose. Accordingly, we believe that the MTD in the present study should not be extrapolated to patients who will receive bevacizumab following HIPEC and vice versa.

The treatment effect of HIPEC comes not only from the chemotherapeutic drugs but also from the cytotoxicity of hyperthermia $(34,35)$. In our trial, the HIPEC was administered at $43^{\circ} \mathrm{C}$, which is in accordance with the CACA guidelines (7). The safety and effectiveness of HIPEC at $43^{\circ} \mathrm{C}$ have been validated in previous clinical studies $(18,36,37)$. Since the cytotoxicity of hyperthermia is temperature dependent and has a strong influence on the safe application of $\operatorname{HIPEC}(34,35)$, it is necessary to investigate MTDs for chemotherapeutic drugs in HIPEC at a given temperature.

The sample size and the design of the present trial limited our ability to draw reliable conclusions regarding the efficacy of HIPEC. Second, 30\% of the current cohort received only biopsy because of unresectable disease. The amount of residual disease can influence the penetration ability of cisplatin, and blood loss, which also impacts the risk of HIPEC-related renal dysfunction, could be different between patients receiving biopsy and patients receiving debulking surgery (38). Since we did not conduct pharmacokinetics and pharmacodynamics assessment or subgroup analysis, it is unclear whether the MTDs of hyperthermic cisplatin would be different between the two cohorts. Third, given the heterogeneity of our cohort, it is impossible to identify the type of patient who can benefit the most from HIPEC. Another limitation is the short follow-up duration. Therefore, the long-term adverse reactions that are associated with using cisplatin in HIPEC cannot be evaluated. Additionally, laparoscopic HIPEC for low-volume peritoneal metastasis has been reported in previous studies (39). An elevated intraabdominal pressure can be induced when laparoscopic technique is used, which could improve tissue penetration and thus enhance the cytotoxicity of cisplatin. Therefore, a more specialized dose regimen may be needed in this setting ADDIN EN.CITE (39).

\section{REFERENCES}

1. Lemoine L, Sugarbaker P, Van der Speeten K. Drugs, doses, and durations of intraperitoneal chemotherapy: standardising HIPEC and EPIC for colorectal, appendiceal, gastric, ovarian peritoneal surface malignancies and peritoneal mesothelioma. Int J Hyperthermia. (2017) 33:582-92. doi: 10.1080/02656736.2017.1291999

2. Gonzalez-Moreno S, Gonzalez-Bayon LA, Ortega-Perez G. Hyperthermic intraperitoneal chemotherapy: rationale and technique. World J Gastrointest Oncol. (2010) 2:68-75. doi: 10.4251/wjgo.v2.i2.68

3. Spiliotis J, Halkia E, Lianos E, Kalantzi N, Grivas A, Efstathiou E, et al. Cytoreductive surgery and HIPEC in recurrent epithelial ovarian cancer: a
In conclusion, we utilized a BOIN design in this Phase I dosefinding trial and established a dose of $85 \mathrm{mg} / \mathrm{m}^{2}$ as the MTD for hyperthermic cisplatin at $43^{\circ} \mathrm{C}$. Given the characteristics of our patients, our findings are applicable to patients who do not receive bevacizumab. Further Phase II trials are warranted to validate our conclusion.

\section{DATA AVAILABILITY STATEMENT}

The raw data supporting the conclusions of this article will be made available by the authors, without undue reservation.

\section{ETHICS STATEMENT}

The studies involving human participants were reviewed and approved by Institutional Review Board of Sun Yat-sen Memorial Hospital. The patients/participants provided their written informed consent to participate in this study.

\section{AUTHOR CONTRIBUTIONS}

C-yC and HL: data curation, methodology, formal analysis, methodology, writing - original draft, and project administration. M-fW and C-hL: data curation. JL: conceptualization, methodology, supervision, resources, and writing - review and editing. Z-qL: conceptualization, supervision, resources, and writing-review and editing. All authors contributed to the article and approved the submitted version.

\section{FUNDING}

This research was funded by China Scholarship Council (grant number 201906385061).

\section{ACKNOWLEDGMENTS}

We would like to acknowledge all of the research coordinators at the Department of Gynecologic Oncology at Sun Yat-sen Memorial Hospital. We are deeply grateful to the patients and their families for participating in this study and clinicians who referred cases.

prospective randomized phase III study. Ann Surg Oncol. (2015) 22:15705. doi: 10.1245/s10434-014-4157-9

4. van Driel WJ, Koole SN, Sikorska K, Schagen van Leeuwen JH, Schreuder HWR, Hermans RHM, et al. Hyperthermic intraperitoneal chemotherapy in ovarian cancer. N Engl J Med. (2018) 378:230-40. doi: 10.1056/NEJMoa1708618

5. Huo YR, Richards A, Liauw W, Morris DL. Hyperthermic intraperitoneal chemotherapy (HIPEC) and cytoreductive surgery (CRS) in ovarian cancer: a systematic review and meta-analysis. Eur J Surg Oncol. (2015) 41:157889. doi: 10.1016/j.ejso.2015.08.172

6. Armstrong DK, Alvarez RD, Bakkum-Gamez JN, Barroilhet L, Behbakht K, Berchuck A, et al. NCCN Guidelines Insights: 
Ovarian Cancer, Version 1.2019. J Natl Compr Canc Netw. (2019) 17:896-909. doi: 10.6004/jnccn.2019.0039

7. Li Y, Zhou YF, Liang H, Wang HQ, Hao JH, Zhu ZG, et al. Chinese expert consensus on cytoreductive surgery and hyperthermic intraperitoneal chemotherapy for peritoneal malignancies. World J Gastroenterol. (2016) 22:6906-16. doi: 10.3748/wjg.v22.i30.6906

8. Auer RC, Sivajohanathan D, Biagi J, Conner J, Kennedy E, May T. Indications for hyperthermic intraperitoneal chemotherapy with cytoreductive surgery: a clinical practice guideline. Curr Oncol. (2020) 27:146-54. doi: 10.3747/co.27.6033

9. Pavlov MJ, Ceranic MS, Latincic SM, Sabljak PV, Kecmanovic DM, Sugarbaker PH. Cytoreductive surgery and hyperthermic intraperitoneal chemotherapy for the treatment of advanced epithelial and recurrent ovarian carcinoma: a single center experience. Int J Hyperthermia. (2018) 34:5649. doi: 10.1080/02656736.2017.1371341

10. Oh GS, Kim HJ, Shen A, Lee SB, Khadka D, Pandit A, et al. Cisplatininduced kidney dysfunction and perspectives on improving treatment strategies. Electrolyte Blood Press. (2014) 12:55-65. doi: 10.5049/EBP.2014. 12.2 .55

11. Gouy S, Ferron G, Glehen O, Bayar A, Marchal F, Pomel C, et al. Results of a multicenter phase I dose-finding trial of hyperthermic intraperitoneal cisplatin after neoadjuvant chemotherapy and complete cytoreductive surgery and followed by maintenance bevacizumab in initially unresectable ovarian cancer. Gynecol Oncol. (2016) 142:237-42. doi: 10.1016/j.ygyno.2016. 05.032

12. Zivanovic O, Abramian A, Kullmann M, Fuhrmann C, Coch C, Hoeller T, et al. HIPEC ROC I: a phase I study of cisplatin administered as hyperthermic intraoperative intraperitoneal chemoperfusion followed by postoperative intravenous platinum-based chemotherapy in patients with platinum-sensitive recurrent epithelial ovarian cancer. Int J Cancer. (2015) 136:699-708. doi: 10.1002/ijc.29011

13. Sin EI, Chia CS, Tan GHC, Soo KC, Teo MC. Acute kidney injury in ovarian cancer patients undergoing cytoreductive surgery and hyperthermic intra-peritoneal chemotherapy. Int $J$ Hyperthermia. (2017) 33:690-5. doi: 10.1080/02656736.2017.12 93304

14. Khrunin A, Ivanova F, Moisseev A, Khokhrin D, Sleptsova Y, Gorbunova $\mathrm{V}$, et al. Pharmacogenomics of cisplatin-based chemotherapy in ovarian cancer patients of different ethnic origins. Pharmacogenomics. (2012) 13:1718. doi: $10.2217 /$ pgs. 11.140

15. Izzedine H. Anti-VEGF Cancer Therapy in Nephrology Practice. Int $J$ Nephrol. (2014) 2014:143426. doi: 10.1155/2014/143426

16. Furman MJ, Picotte RJ, Wante MJ, Rajeshkumar BR, Whalen GF, Lambert LA. Higher flow rates improve heating during hyperthermic intraperitoneal chemoperfusion. J Surg Oncol. (2014) 110:970-5. doi: 10.1002/jso.23776

17. Cata JP, Zavala AM, Van Meter A, Williams UU, Soliz J, Hernandez $\mathrm{M}$, et al. Identification of risk factors associated with postoperative acute kidney injury after cytoreductive surgery with hyperthermic intraperitoneal chemotherapy: a retrospective study. Int J Hyperthermia. (2018) 34:53844. doi: 10.1080/02656736.2017.1368096

18. Gao T, Huang XX, Wang WY, Wu MF, Lin ZQ, Li J. Feasibility and safety of neoadjuvant laparoscopic hyperthermic intraperitoneal chemotherapy in patients with advanced stage ovarian cancer: a single-center experience. Cancer Manag Res. (2019) 11:6931-40. doi: 10.2147/CMAR.S213882

19. Liu S, Yuan Y. Bayesian optimal interval designs for phase I clinical trials. J R Stat Soc C. (2015) 64:507-23. doi: 10.1111/rssc.12089

20. Howell SB, Pfeifle CE, Wung WE, Olshen RA. Intraperitoneal cisdiamminedichloroplatinum with systemic thiosulfate protection. Cancer Res. (1983) 43:1426-31.

21. Yuan Y, Hess KR, Hilsenbeck SG, Gilbert MR. Bayesian optimal interval design: a simple and well-performing design for phase I oncology trials. Clin Cancer Res. (2016) 22:4291-301. doi: 10.1158/1078-0432.CCR16-0592

22. Verwaal VJ, van Ruth S, de Bree E, van Sloothen GW, van Tinteren $\mathrm{H}$, Boot $\mathrm{H}$, et al. Randomized trial of cytoreduction and hyperthermic intraperitoneal chemotherapy versus systemic chemotherapy and palliative surgery in patients with peritoneal carcinomatosis of colorectal cancer. J Clin Oncol. (2003) 21:3737-43. doi: 10.1200/JCO.2003.04.187
23. Kusamura S, Baratti D, Younan R, Laterza B, Oliva GD, Costanzo P, et al. Impact of cytoreductive surgery and hyperthermic intraperitoneal chemotherapy on systemic toxicity. Ann Surg Oncol. (2007) 14:25508. doi: 10.1245/s10434-007-9429-1

24. Canda AE, Sokmen S, Terzi C, Arslan C, Oztop I, Karabulut B, et al. Complications and toxicities after cytoreductive surgery and hyperthermic intraperitoneal chemotherapy. Ann Surg Oncol. (2013) 20:1082-7. doi: 10.1245/s10434-012-2853-x

25. Bouhadjari N, Gabato W, Calabrese D, Msika S, Keita H. Hyperthermic intraperitoneal chemotherapy with cisplatin: amifostine prevents acute severe renal impairment. Eur J Surg Oncol. (2016) 42:219-23. doi: 10.1016/j.ejso.2015.07.016

26. Crona DJ, Faso A, Nishijima TF, McGraw KA, Galsky MD, Milowsky MI. A systematic review of strategies to prevent cisplatin-induced nephrotoxicity. Oncologist. (2017) 22:609-19. doi: 10.1634/theoncologist.2016-0319

27. Beladi Mousavi SS, Hossainzadeh M, Khanzadeh A, Hayati F, Beladi Mousavi M, Zeraati AA, et al. Protective effect of forced hydration with isotonic saline, potassium chloride and magnesium sulfate on cisplatin nephrotoxicity: an initial evaluation. Asia Pac J Med Toxicol. (2013) 2:1369. doi: 10.22038/APJMT.2013.2036

28. Launay-Vacher V, Rey JB, Isnard-Bagnis C, Deray G, Daouphars M, European Society of Clinical Pharmacy Special Interest Group on Cancer C. Prevention of cisplatin nephrotoxicity: state of the art and recommendations from the European Society of Clinical Pharmacy Special Interest Group on Cancer Care. Cancer Chemother Pharmacol. (2008) 61:903-9. doi: 10.1007/s00280-008-0711-0

29. Malyszko J, Kozlowska K, Kozlowski L, Malyszko J. Nephrotoxicity of anticancer treatment. Nephrol Dial Transplant. (2017) 32:92436. doi: 10.1093/ndt/gfw338

30. Paris I, Cianci S, Vizzielli G, Fagotti A, Ferrandina G, Gueli Alletti S, et al. Upfront HIPEC and bevacizumab-containing adjuvant chemotherapy in advanced epithelial ovarian cancer. Int J Hyperthermia. (2018) 35:3704. doi: 10.1080/02656736.2018.1503346

31. Lafayette RA, McCall B, Li N, Chu L, Werner P, Das A, et al. Incidence and relevance of proteinuria in bevacizumab-treated patients: pooled analysis from randomized controlled trials. Am J Nephrol. (2014) 40:7583. doi: $10.1159 / 000365156$

32. Kataoka S, Nishikawa Y, Funakoshi T, Horimatsu T, Kondo N, Matsubara T, et al. Long-term survival and renal dysfunction in a patient with recurrent colorectal cancer treated with Bevacizumab. Clin J Gastroenterol. (2019) 13:316-9. doi: 10.1007/s12328-019-01060-Z

33. Detroz B, Laurent S, Honore P, Blaffart F, Limet R, Meurisse M. Rationale for hyperthermic intraperitoneal chemotherapy (HIPEC) in the treatment or prevention of peritoneal carcinomatosis. Acta Chir Belg. (2004) 104:37783 doi: 10.1080/00015458.2004.11679577

34. Leopold KA, Dewhirst M, Samulski T, Harrelson J, Tucker JA, George SL, et al. Relationships among tumor temperature, treatment time, and histopathological outcome using preoperative hyperthermia with radiation in soft tissue sarcomas. Int J Radiat Oncol Biol Phys. (1992) 22:98998. doi: 10.1016/0360-3016(92)90798-M

35. Rossmanna C, Haemmerich D. Review of temperature dependence of thermal properties, dielectric properties, and perfusion of biological tissues at hyperthermic and ablation temperatures. Crit Rev Biomed Eng. (2014) 42:467-92. doi: 10.1615/CritRevBiomedEng.2015012486

36. Li XB, Ma R, Ji ZH, Lin YL, Zhang J, Yang ZR, et al. Perioperative safety after cytoreductive surgery plus hyperthermic intraperitoneal chemotherapy for Pseudomyxoma peritonei from appendiceal origin: experience on 254 patients from a single center. Eur J Surg Oncol. (2020) 46(4 Pt A):6006. doi: 10.1016/j.ejso.2020.01.017

37. Tu Y, Tian Y, Fang Z, Ruan Q, Tang H, Zhang X, et al. Cytoreductive surgery combined with hyperthermic intraperitoneal chemoperfusion for the treatment of gastric cancer: a single-centre retrospective study. Int $J$ Hyperthermia. (2016) 32:587-94. doi: 10.1080/02656736.2016.1190987

38. Sugarbaker PH, Van der Speeten K. Surgical technology and pharmacology of hyperthermic perioperative chemotherapy. J Gastrointest Oncol. (2016) 7:29-44. doi: 10.3978/j.issn.2078-6891.2015.105

39. Gallotta V, Fagotti A, Fanfani F, Ferrandina G, Nero C, Costantini B, et al. Laparoscopic surgical management of 
localized recurrent ovarian cancer: a single-institution experience.

Surg Endosc. (2014) 28:1808-15. doi: 10.1007/s00464-013-3

390-9

Conflict of Interest: The authors declare that the research was conducted in the absence of any commercial or financial relationships that could be construed as a potential conflict of interest.
Copyright $\odot 2021$ Chan, Li, Wu, Liu, Lu, Lin and Li. This is an open-access article distributed under the terms of the Creative Commons Attribution License (CC BY). The use, distribution or reproduction in other forums is permitted, provided the original author(s) and the copyright owner(s) are credited and that the original publication in this journal is cited, in accordance with accepted academic practice. No use, distribution or reproduction is permitted which does not comply with these terms. 